\title{
Cognitive, Social, and Teaching Presence as Predictors of Students' Satisfaction in Distance Learning
}

\author{
Maria Giannousi ${ }^{1}$ \\ Efthimis Kioumourtzoglou² \\ ${ }^{1}$ Research Associate, Department of Physical Education and Sport Sciences, Democritus University of Thrace \\ Komotini, Greece, mgiannou@phyed.duth.gr \\ 2Professor, Department of Sport Sciences, University of Nicosia, Cyprus, kioumourtzoglou.e@unic.ac.cy
}

\section{Doi:10.5901/mjss.2016.v7n2s1p439}

\begin{abstract}
The purpose of this study was to examine whether cognitive, social, and teaching presence were significant predictors of the overall students' satisfaction in hybrid learning courses. The used research design was non-experimental and correlational in nature. Hierarchical multiple regression analysis was used to determine to what extent cognitive, social, and teaching presence predicted the overall students' satisfaction. The data in this quantitative study was collected using a self-report survey. Participants were two hundred fourteen $(n=214)$ undergraduate students, between the ages from 19-24 years old. The findings of this study showed that cognitive, social, and teaching presence explained $39 \%$ of the variance in students' satisfaction. Cognitive presence was found to have the largest contribution in predicting students' satisfaction and it was a better predictor of students satisfaction compared with teaching and social presence. Due to the importance of cognitive, social, and teaching presence in predicting students' satisfaction, it is recommended that improving these factors in the distance courses be taken into consideration. Furthermore, since cognitive presence in this study was found to be a strong predictor of students' satisfaction, it is recommended that faculty need to focus on this presence especially, and assure that students are able to reach the final stage of cognitive presence.
\end{abstract}

Keywords: Cognitive Presence, Social Presence, Teaching Presence, Satisfaction, Distance Learning, Undergraduate Students.

\section{Introduction}

Distance education through the online and the hybrid courses have changed people's perspectives of education and have opened educational opportunities for people who previously had no way of continuing their education (Aljabre, 2012; Bebetsos, 2015). In distance education, students are not constrained any more with courses and programs that required them to be personally present on campuses. Indeed, the utilization of Information Technology and the Internet have had a positive influence on learning and education of both students (Vernadakis, Antoniou, Zetou, \& Kioumourtzoglou, 2004; Vernadakis, Zetou, Avgerinos, Giannousi, \& Kioumourtzoglou, 2006; Vernadakis, Zetou, Antoniou, \& Kioumourtzoglou, 2002; Vernadakis, Papastergiou, Zetou, Antoniou, 2015; Vernadakis, Derri, Tsitskari, Antoniou, 2014) and teachers in physical education (Derri, Emmanouilidou, Antoniou, \& Chatzaraki, 2012; Emmanouilidou, Derri, Antoniou, \& Kyrgiridis, 2012). Cho (2011) noted that many educators believe that the Internet can play an important role in improving current education. Distance education plays a role in connecting students with universities around the world; Vernadakis, Zetou, Tsitskari, Giannousi, \& Kioumourtzoglou (2008) added that this kind of education provides a wide range of programs for students that allow them to learn at one's own pace while remaining in their homes or with their families. The same was supported for in-service teachers (Emmanouilidou et al., 2012). Another advantage of distance education is that online and hybrid courses provide students with flexibility of learning (Farzaneh, 2011; Giannousi, Vernadakis, Derri, Antoniou, Kioumourtzoglou, 2014).

Nevertheless, some educational experts and learners have concerns regarding distance education; they have doubts related to the lack of social communication and a fear that in distance education students' classes, the engagement level is less than what is present in traditional face-to-face courses (Robb \& Sutton, 2014). These concerns make distance education a rich topic to be investigated by researchers. One aspect of this topic that has been discussed in previous studies is students' satisfaction in distance learning (Bebetsos \& Goulimaris, 2014) and teachers' satisfaction in distance learning (Emmanouilidou, Antoniou, \& Derri, 2010). Exploring students' satisfaction level in the distance learning experience is necessary for a variety of reasons (Al-Asfour, 2012). In online or hybrid courses especially, having unsatisfied students can be associated with low completion rates and low student motivation levels (Kuo, Walker, 
Belland, \& Schroder, 2013), either of which could take away from the benefits of this new technology and halt its progress. Al-Asfour (2012) suggested that instructors need to discover and understand issues related to students' satisfaction with online or hybrid courses in order to make suitable interventions that may resolve any influential factors on students' satisfaction. Students' satisfaction is an essential element of online and hybrid courses since it is an indicator of course quality and the successfulness of the overall learning experience (Cho, 2011; Jackson, Jones, \& Rodriguez, 2010). This particular study focused on satisfaction and investigated specific factors that could predict this variable. Predictors, which were investigated in this study, were cognitive presence, social presence, and teaching presence. Cognitive presence, social presence, and teaching presence are components of the Community of Inquiry framework which was developed originally by Garrison, Anderson, \& Archer (2000). To explain the meaning of the Community of Inquiry (Col) framework, Kupczynski, Ice, Wiesenmayer, \& McCluskey (2010) defined this framework as a theoretical framework that explains the online and hybrid learning experience in terms of interactions between three overlapping presences: Teaching, Social and Cognitive. In line, such presences are, among others, fundamentals in effective instruction of physical education (Derri, Vasiliadou, \& Kioumourtzoglou, 2015; Kyrgiridis, Derri, Emmanouilidou, Chlapoutaki, \& Kioumourtzoglou, 2014; Zetou, Nikolaos, \& Evaggelos, 2014; Zetou, Malliou, Lola, Tsigganos, \& Godolias, 2006; Zetou, Vernadakis, Bebetsos, \& Makraki, 2012).

\section{Literature Review}

Several studies have reported potential benefits of social presence (Alman, Frey, \& Tomer, 2012; Bulu, 2012; Filippou, 2015; Sung \& Mayer, 2012; Wei, Chen, \& Kinshuk, 2012; Zetou, Amprasi, Michalopoulou, Aggelousis, 2011), teaching presence (Antoniou, Gourgoulis, Trikas, Mavridis, \& Bebetsos, 2003; Garrison, Cleveland-Innes, \& Fung, 2010; Lear, Isernhagen, LaCost, \& King, 2009), and cognitive presence in distance learning (Hosler \& Arend, 2012; Alman et al., 2012). The benefits of cognitive, social, and teaching presence have made them a rich topic for researchers in the domain of distance learning.

However, due to the structure of online or hybrid courses, students could easily feel isolated compared with faceto-face courses; thus, assuring a high level of social presence among students could result in a more successful online or hybrid learning experience (Scollins-Mantha, 2008). Social presence has been defined in online and hybrid courses by Shea, Pickett, and Pelz (2003) as the ability of students to project themselves socially and affectively into a community of inquiry. When students fail to perceive social presence in online or hybrid courses, anticipated issues may result such as a high drop-out rate, low achievement, and low learning satisfaction (Scollins-Mantha, 2008). Robb \& Sutton (2014) indicated that social presence has been given the most attention in the literature. Many studies have highlighted the topic of social presence in distance learning. In the literature, social presence in distance learning has been shown to have an impact on students' satisfaction (Bulu, 2012), student enjoyment (Bebetsos \& Antoniou, 2008; Mackey \& Freyberg, 2010), interaction level (Sung \& Mayer, 2012; Wei et al., 2012), and collaborative learning (Mackey \& Freyberg, 2010). The importance of social presence in distance education is potentially due to its positive influence of leading students to build a community of learning and make a connection with classmates (Sung \& Mayer, 2012).

In terms of teaching presence, Jackson et al. (2010) found a correlation between instructors' actions and students' satisfaction in online courses; their study further showed that instructor's actions could have an impact students' satisfaction. Dunlap \& Lowenthal, (2009) stated that teaching presence is the ability of a teacher or teachers to support and enhance social and cognitive presence through instructional management, building understanding, and direct instruction. Ladyshewsky (2013) also reported that teaching presence appeared to positively influence students' satisfaction with an online course of study. Teaching presence emphasizes the teacher's role and responsibilities in their learning environment. Some studies have shown that one role of teaching presence is to facilitate social presence and cognitive presence, both of which emphasized its importance in the distance learning experience (Garrison et al., 2010; Lear et al., 2009).

Regarding cognitive presence, assuring this presence in online or hybrid environment can sustain a high level of thinking and facilitate learning (Kanuka \& Garrison, 2004). Cognitive Presence is defined as a process of practical inquiry distinguished by discourse and reflection for the purpose of constructing meaning and confirming understanding (Garrison et al., 2000). Cognitive presence has been studied less than the two other presences (Arbaugh et al., 2008; Hosler \& Arend, 2012). Bangert (2008) stated that cognitive presence does not co-exist with teaching and social presence; instead cognitive presence is an outcome of their existence in the learning setting. Garrison et al., (2010) stated that cognitive presence is most closely associated with the process and outcomes of critical thinking and may be the most challenging element to facilitate and measure in the online or hybrid environment.

Furthermore, many studies have focused on studying students' satisfaction with online or hybrid courses due to its 
effect on the successfulness of the online or the hybrid experience (Al-Asfour, 2012; Alman et al., 2012; Vernadakis, Giannousi, Tsitskari, Antoniou, \& Kioumourtzoglou, 2012). Also, Emmanouilidou et al. (2010) highlighted the participants' satisfaction from on line instruction and their conviction that it fostered their active and collaborative learning. There is a wide range of studies that focused on the factors that influence satisfaction (Vernadakis, Antoniou, Giannousi, Zetou, Kioumourtzoglou, 2011; Vernadakis, Kouli, Tsitskari, Gioftsidou, \& Antoniou, 2014); there are studies which chose to explore predictors of satisfaction, specifically the role of satisfaction in relationship with social presence (Cobb, 2011; Robb, \& Sutton, 2014), teaching presence (Bebetsos \& Goulimaris, 2014; Hosler \& Arend, 2012; Mayne \& Wu, 2011), and cognitive presence (Hosler \& Arend, 2012; Alman et al., 2012). However, the review of literature indicates that there are a limited number of studies that discuss cognitive, social, and teaching presence as predictors of students' satisfaction in online or hybrid courses. Based on this, there is a need for more studies to investigate the relationship between cognitive, social, and teaching presence and students' satisfaction and to investigate which presence best predicts students' satisfaction. Therefore, the purpose of this study was to examine whether cognitive, social, and teaching presence were significant predictors of the overall students' satisfaction in hybrid learning courses. It was intended to investigate if there was a relationship between students' satisfaction and these three presences, cognitive, social, and teaching presence. It was also intended to uncover if cognitive, social, and teaching presence were significant predictors of students' satisfaction, and which predictor did the best in predicting students' satisfaction. The study looked at the following general research statement: To what extent does cognitive presence predict students' satisfaction after adding it with teaching and social presence in hybrid learning courses?

The results of this study would be helpful for researchers who are interested on evaluating students' successfulness in online and hybrid environments. Investigating the importance of cognitive, social, and teaching presence as a significant predictor of students' satisfaction, would be beneficial for researchers who are interested in making suitable interventions to facilitate online and hybrid courses. With the knowledge that these presences have an influence on the ability to understand the online and hybrid learning experience, instructors may be motivated to implement or make changes on the instructional design, facilitate discourse and improve the quality of online and hybrid learning. In other words, would increase the awareness of the appropriate planning steps for online and hybrid courses.

\section{Methods}

\subsection{Participants}

The participants included in this study were undergraduate students enrolled in courses at the Democritus University of Thrace, School of Physical Education \& Sport Science in winter and spring semesters of 2013. The sampling frame used for this study was convenience sampling. For data collection, the researchers asked three instructors who were delivering hybrid instructions in different subject disciplines at the university to allow students' participation in the study. As a result, two hundred fourteen $(n=214)$ students participated in the data collection. The participants consisted of $77(36 \%)$ freshmen, 59 (27.6\%) sophomores or juniors, and 78 (36.4\%) seniors. One hundred thirty one (61.2\%) of the participants were male and eighty three were female (38.8\%), between the ages from 19-24 years old. The students' participation was voluntary, and the anonymity of students' responses and their confidentiality as participants were explained before distributing the instruments.

\subsection{Instrumentation}

The Col survey developed by Arbaugh et al. (2008) with 34 items and the satisfaction survey developed by Kuo, Walker, Schroder, \& Belland (2014) with 5 items were used for data collection purposes. Col survey obtained information regarding students' perception in order to measure the presences within online and hybrid learning environments based on a single instrument. The survey consists of three subparts (corresponding to the three presences) each of which includes a different number of items that purport to measure each presence type (cognitive - 12 items, social - 9 items, and teaching presence - 13 items). Survey instruments measure the three presences and the satisfaction using a fivepoint Likert-type scale ranged from 1 (strongly disagree) to 5 (strongly agree). The validity and reliability of these survey instruments were previously established. Arbaugh et al. (2008) principal component analysis found that data supports the construct validity of the presences as measured by the Col instrument. The same study also produced Cronbach's alpha indexes indicative of high internal consistency: (a) teaching presence $=.94$; (b) social presence $=.91$; (c) cognitive presence $=.95$. Similar, Kuo et al. (2014) in their study confirmed the construct validity of the satisfaction survey, while internal consistency estimated by Cronbach's alpha measure was also high .93. 


\subsection{Data Collection}

An online version of the Col and satisfaction survey instruments were posted on a course management system used by the instructors to deliver their courses. The data were collected at the end of each course as a part of course evaluation procedure. When each session was over, the participants were asked to complete the Col and satisfaction questionnaires with as much care as possible in a retrospective way.

The online questionnaire was designed in such a way that when participants first clicked on the link to the questionnaire, they were shown an informed consent letter explaining the purpose and structure of the questionnaire, their rights as participants, as well as any possible risk involved in participation of this research. In the letter, participants were also given the email address of the researcher in case there were other questions regarding the research that a participant wished to clarify. The email could also be used if a participant was interested in knowing the results of the research study.

The online questionnaire was divided into five different sections. After reading the informed consent letter, the participants were directed to the first section of the questionnaire where questions relative with the participants' demographic information (age, gender, academic year) were included. The four other sections focused on asking students about their perception of teaching presence, social presence, cognitive presence, and overall satisfaction. Participants completed the questionnaire in a section-by-section manner, that is, after the completion of one section, the participant was asked to click a next button to go to the next section, until all sections were completed. The questionnaire was also designed with an embedded program so that if a participant chose to skip any item, a remark designed using JavaScript appeared requiring the participant to complete the missing item before he or she proceeded to the next section. After completion of the entire questionnaire, the participant clicked on a submit button, which sent the completed questionnaire to a secure server accessible only by the researcher. It was determined that participants would need approximately 30 minutes to complete all sections of this instrument.

\subsection{Data Analysis}

The research design used in this study was non-experimental and correlational in nature. According to Green \& Salkind (2013), correlational research investigates the relationship between variables and the extent of this relationship. When a researcher is exploring the relationship between more than two variables, a special kind of statistics known as multivariate correlational statistics is used; one kind of these multivariate correlational statistics is hierarchical multiple regression analysis (Green \& Salkind, 2013).

Hierarchical multiple regression analysis was chosen to determine if cognitive, social, and teaching presence are significant predictors of students' satisfaction. A Statistical Package for the Social Science (SPSS) version 22 was used to analyze data. Descriptive statistics including mean and standard deviation were provided in order to explain clearly the sample of this study. Correlation coefficients were computed to determine if there were significant relationships between variables. Assumptions of hierarchical multiple regression analysis were tested.

The regression equation model for the main research question was as follows: Predicted Value of Students' Satisfaction $=\beta 0+\beta 1 \times 1+\beta 2 \times 2+\beta 3 \times 3$; whereas $\beta 0$ was constant, $\beta 1$ was the coefficient on the teaching presence, $\beta 2$ was the coefficient on the social presence, $\beta 3$ was the coefficient on the cognitive presence, $x 1$ was teaching presence score, $x 2$ was social presence score, and $\times 3$ was cognitive presence score.

\section{Results}

\subsection{Reliability of the scales}

The Cronbach's alpha coefficients were calculated in this present study and they were .91 for the social presence scale, .93 for the teaching presence scale, and finally .94 for the cognitive presence scale (Table 1). Green \& Salkind (2013) suggested that a scale with a Cronbach alpha of .9 has an excellent internal consistency. Thus, the cognitive presence scale, the teaching presence scale and the social presence scale have an excellent internal consistency.

\subsection{To what extent does cognitive presence predict students' satisfaction after adding it with teaching and social presence in hybrid learning courses}

In order to assess whether cognitive presence was a significant predictor of students' satisfaction when added to the 
model that had social and teaching presence, a hierarchical multiple regression was performed using students' satisfaction as the dependent variable. First, social presence and teaching presence were entered to the regression, and then cognitive presence was entered. This new model had three predictors: cognitive presence, social presence, and teaching presence.

Examining Pearson correlation in Table 1 showed that the three predictors and students satisfaction were positively correlated. The correlation between teaching presence and students satisfaction was statistically significant, $r=$ $.467, p<.05$ (two tailed). The correlation between social presence variable and students satisfaction was statistically significant, $r=.511, p<.05$ (two tailed). Pearson correlation was also significant between cognitive presence and students satisfaction, $r=.596, p<.05$ (two tailed). Participants who had a high perception toward teaching presence had a high satisfaction with the hybrid learning courses. Participants who had a high perception toward social presence also had a high satisfaction with the hybrid learning courses. Finally, participants who had a high perception toward cognitive presence had also a high satisfaction. For the overall regression to predict students satisfaction from social presence, teaching presence, and cognitive presence, $R=.628$ and $R^{2}=.39$ (Table 2). That means, social presence, teaching presence, and cognitive presence as a group predicted $39 \%$ of the variance in students' satisfaction. The adjusted $R^{2}$ was .390. The overall regression, which had all the three predictors, was statistically significant, $F(3,211)=167.29, p<$ .05 .

Table 1. Correlations among the three presences (teaching, social, cognitive) and students' satisfaction.

\begin{tabular}{llccc}
\cline { 2 - 5 } & & Satisfaction & Teaching presence & Social presence \\
\cline { 2 - 5 } & Teaching presence & $.467^{*}$ & & \\
& Social presence & $.511^{*}$ & $.502^{*}$ & \\
& Cognitive presence & $.596^{*}$ & $.660^{*}$ & $.616^{*}$ \\
\cline { 2 - 5 }
\end{tabular}

When looking at the coefficients table (Table 3), teaching presence was a significant predictor of students satisfaction when social presence and cognitive presence were controlled $t(210)=2.58, p<.05$. Social presence was also a significant predictor of students satisfaction when teaching presence and cognitive presence were controlled $t(210)=$ $6.10, p<.05$. Cognitive presence was also a significant predictor of students satisfaction when teaching presence and social presence were controlled $t(210)=9.80, p<.05$.

Table 2. Model summary of the hierarchical multiple regression analysis.

\begin{tabular}{cccccccc}
\hline Mode & $\mathrm{R}$ & $\mathrm{R}$ square Adjusted R square Std. error of the estimate & \multicolumn{4}{c}{ Change statistics } \\
\cline { 5 - 7 } & & & & R square change F change df1 df2 \\
\hline 1 & $.558^{\mathrm{a}}$ & .311 & .309 & .57165 & .311 & $180.32^{*}$ & 211 \\
2 & $628^{\mathrm{b}}$ & .392 & .390 & .54099 & .081 & $95.91^{*}$ & 1210 \\
\hline
\end{tabular}

a. Predictors: (constant), social presence, teaching presence

b. Predictors: (constant), social presence, teaching presence, cognitive presence

${ }^{*} p<0.05$

After comparing the standardized coefficients for the three predictors, it is clear that among the three predictors, cognitive presence was responsible for the most change in students satisfaction with $\beta=.405$. It followed with social presence with $\beta=.225$ and then teaching presence with $\beta=.106$. It seems that teaching presence was responsible for the least change in students' satisfaction. It is noticeable that entering cognitive presence to the model had reduced the effect of teaching and social presence. The addition of cognitive presence to the first model, which had only social and teaching presence, resulted in an additional $8.1 \%$ of the variance being explained $\left(R^{2}\right.$ change $\left.=.081\right)$. Cognitive presence was found to be a better predictor of students' satisfaction compared with the two other predictors. The multiple regression model equation for predicting the students satisfaction score from the three predictors is $Y 1=1.432+.114 X 1+.236 \mathrm{X} 2+.434 \mathrm{X} 3$; whereas $\mathrm{X} 1$ is the score for the teaching presence scale, $\mathrm{X} 2$ is the score for the social presence scale, and $\mathrm{X} 3$ is the score for the cognitive presence scale. 
Table 3. Coefficients table of the hierarchical multiple regression model.

\begin{tabular}{lccccc}
\hline Model & B & Std. error & Beta & t & Correlation part \\
\hline Constant & $1.713^{\star}$ & .149 & & $12.378^{*}$ & \\
Teaching presence & .313 & .048 & .288 & $8.273^{*}$ & .252 \\
Social presence & .392 & .046 & .374 & $10.841^{*}$ & .327 \\
Constant & 1.432 & .144 & & $10.670^{*}$ & \\
Teaching presence & .114 & .051 & .106 & $2.584^{*}$ & .082 \\
Social presence & .236 & .048 & .225 & $6.097^{*}$ & .179 \\
Cognitive presence & .434 & .054 & .405 & $9.799^{*}$ & .282 \\
\hline
\end{tabular}

\section{Discussion}

Social presence and teaching presence together were found in this study to significantly predict students' satisfaction and they both predicted $31.1 \%$ of the variance in students' satisfaction. When adding cognitive presence to the overall hierarchical regression, which predicted students' satisfaction from cognitive presence, social presence, and teaching presence, the overall hierarchical regression model was also statistically significant. All of the three factors were able to explain $39.2 \%$ of the variance in students' satisfaction. The addition of cognitive presence by itself resulted in a significant contribution into the regression equation. Adding cognitive presence contributed an additional $8.1 \%$ of the variance being explained in the final model. The results showed that among the three factors (teaching presence, social presence, and cognitive presence) cognitive presence was found to be the strongest predictor of students' satisfaction. Akyol and Garrison (2008) supported this result when they stated that cognitive presence goes to the heart of the Col framework.

Cognitive presence is important due to its strong correlation with the learning process (Akyol \& Garrison, 2008; Akyol \& Garrison, 2011). Cognitive presence has showed up as the strongest predictor of satisfaction, maybe because it does not coexist with teaching and social presence; instead it is an outcome of their existence in different learning settings (Bangert, 2008; Bebetsos \& Theodorakis, 2003). Cognition aspect in the learning setting is the main target of the learning process; due to this, students could look at it as the main factor affecting their satisfaction in online or hybrid learning courses. Akyol \& Garrison (2009) stated that cognitive presence is highlighted as the purpose for students enrolling in an online or hybrid higher education course. Thus, instructors and administrators in the online or hybrid courses should, first of all, take into consideration, improving cognitive presence, as well as social, and teaching presence in their courses.

Faculty should be well prepared to guide their courses while taking into consideration the elements of Col. This need could be met by providing more workshops that may help to improve faculty knowledge regarding the Col elements in the online and hybrid environment. Such a workshop might focus on strategies that faculty may use to improve cognitive, social, and teaching presence, and should stress their importance to the students. Faculty should be aware of the requirements of how to build online and hybrid courses in a way that may improve their presence and their student's presence, as well as content presence, in order to enhance the whole online or hybrid learning experience.

Moving from traditional classes to online or hybrid courses is challenging, and requires an adjustment to the traditional roles held by the instructor (Vernadakis et al., 2012; Giannousi et al., 2014). Due to this, special workshops should be held to prepare instructors for adjusting to their new teaching responsibility and moving smoothly from face-toface format to online and hybrid format. These workshops should prepare faculty for how to perceive online and hybrid course structure, and educate them on how to build pedagogy that match learners' needs in this learning environment (Emmanouilidou et al., 2012). According to Jackson et al. (2010) instructors should be educated about the importance of their actions in online and hybrid courses; starting from developing the online and hybrid course and then delivering it, instructors should promote their existence in the course. Perhaps, instructors could do that by providing timely feedback, interacting, and preparing well for the class activities and assignments.

Since cognitive presence in this study was found to be a strong predictor of students' satisfaction, it is recommended that faculty need to focus on this presence and assure that students are able to reach the final stage of cognitive presence, which is the resolution phase. Instructors must make sure that students are able to move through the whole cycle of the Practical Inquiry Model (Darabi, Arrastia, Nelson, Cornille, \& Liang, 2011). Activities should be set for students in a way that guides them through the process of critical thinking in many research areas (Bebetsos, Antoniou, Kouli, \& Trikas, 2004; Garrison et al., 2010). Instructors should start such an activity by triggering the learning process, encouraging students to reflect on it within the learning community, and making sure that they construct meaningful knowledge and start learning new knowledge (Garrison et al., 2000). According to Ladyshewsky (2013) instructors can 
help students to reach the last two phases by fostering their ability to challenge themselves and think critically beyond the boundaries of the problem. Encouraging learners to rate their contributions and to become aware of their level of thinking is another way to promote cognitive presence (Arbaugh et al., 2008). Assuring appropriate course design and facilitating activities and discussion could play an additional role in influencing cognitive presence (Hosler, \& Arend, 2012). Bangert (2008) stated that cognitive presence could be reached through support from teaching and social presence; this highlights the importance of these presences as well in the learning setting.

\section{Conclusion}

The frames of the Col, which are cognitive, social, and teaching presence, were found to be significant predictors of students' satisfaction. Cognitive presence was found to be the best predictor of students' satisfaction since it explained the most variance in students' satisfaction. This result suggested integrating the Col framework within the hybrid learning courses due to its importance and positive influence on students' satisfaction. This study recommended replicating this study in other universities that have similar hybrid or online courses, exploring this topic using a qualitative method, and conducting more studies about variables affecting students' satisfaction in online or hybrid learning environments.

\section{References}

Akyol, Z., \& Garrison, D. (2011). Understanding cognitive presence in an online and blended community of inquiry: Assessing outcomes and processes for deep approaches to learning. British Journal of Educational Technology, 42(2), 233- 250.

Akyol, Z., \& Garrison, D. (2008). The development of a community of inquiry over time in an online course: Understanding the progression and integration of social, cognitive and teaching presence. Journal of Asynchronous Learning Networks, 12(3-4), 322.

Al-Asfour, A. (2012). Examining student satisfaction of online statistics courses. Journal of College Teaching and Learning, 9(1), 33-38.

Aljabre, A. (2012). An exploration of distance learning in Saudi Arabian universities: current practices and future possibilities. International Journal of Business, Humanities and Technology, 2(2), 132-137.

Alman, S. W., Frey, B. A., \& Tomer, C. (2012). Social and cognitive presence as factors in learning and student retention: An investigation of the cohort model in an iSchool setting. Journal of Education for Library \& Information Science, 53(4), 290-302.

Antoniou, P., Gourgoulis V., Trikas, G., Mavridis, T., \& Bebetsos, E. (2003). Using Multimedia as an instructional tool in Physical Education. Journal of Human Movements Studies, 44, 433-446.

Arbaugh, J. B., Cleveland-Innes, M., Diaz, S. R., Garrison, D. R., Ice, P., Richardson, J. C., \& Swan, K. P. (2008). Developing a community of inquiry instrument: Testing a measure of the community of inquiry framework using a multi-institutional sample. The Internet and Higher Education, 11(3-4), 133-136.

Bangert, A. (2008). The influence of social presence and teaching presence on the quality of online critical inquiry. Journal of Computing in Higher Education, 20(1), 34-61.

Bebetsos, E. (2015). Prediction of Participation of Undergraduate University Students in a Music and Dance Master's Degree Program. International Journal of Instruction, 8(2), 165-176.

Bebetsos, E., \& Antoniou, P. (2008). University students' differences on attitudes towards computer use. Comparison with students' attitudes towards physical activity. Interactive Educational Multimedia 17, 20-28.

Bebetsos, E., Antoniou, P., Kouli, O., \& Trikas, G. (2004). Knowledge and information in prediction of intention to play badminton. Perceptual and Motor Skills, 98, 1210-1218.

Bebetsos, E., \& Goulimaris, D. (2014). Personal outcome and leadership as defining factors of satisfaction in the context of the course "Arts II: Overview of Greek Music and Dance" of the Hellenic Open University. Turkish Online Journal of Distant Education, 15(2), 12-23.

Bebetsos, E., \& Theodorakis, N. (2003). Athletes' Satisfaction among Team Handball Players in Greece. Perceptual and Motor Skills, $97,1203-1208$.

Bulu, S. T. (2012). Place presence, social presence, co-presence, and satisfaction in virtual worlds. Computers and Education, 58(1), 154-161.

Cho, T. (2011). The impact of types of interaction on student satisfaction in online courses. International Journal on E-Learning, 10(2), 109-125.

Cobb, S. C. (2011). Social presence, satisfaction, and perceived learning of RN-to-BSN students in web-based nursing courses. Nursing Education Perspectives, 32(2), 115-119.

Darabi, A., Arrastia, M. C., Nelson, D. W., Cornille, T., \& Liang, X. (2011). Cognitive presence in asynchronous online learning: A comparison of four discussion strategies. Journal of Computer Assisted Learning, 27(3), 216-227.

Derri, V., Emmanouilidou, K., Antoniou P., \& Chatzaraki, V. (2012). Distance versus face to face professional development environment: Physical educators' knowledge acquisition on student evaluation. Journal of Teaching and Education, 1(5), 179-183.

Derri, V., Vassiliadou, O., \& Kioumourtzoglou, E. (2015). The effects of a short-term professional development program on physical education teachers' behavior and students' engagement in learning. European Journal of Teacher Education, 38(2), 234-262. 
Dunlap, J., \& Lowenthal, P. (2009). Tweeting the night away: Using twitter to enhance social presence. Journal of Information Systems Education, 20(2), 129-135.

Emmanouilidou, K., Derri, V., Antoniou, P., Kyrgiridis, P. (2012). Comparison between synchronous and asynchronous instructional delivery method of training programme on in-service physical educators' knowledge. Turkish Online Journal of Distance Education, 13(4), 193-208.

Emmanouilidou, K., Antoniou, P., \& Derri, V. (2010). Physical educators' perspectives on instructional methodology of synchronous distance professional development. Turkish Online Journal of Distance Education, 11(2), 51-60.

Farzaneh, J. (2011). Distance education based on educational philosophy, postmodernism. Australian Journal of Basic \& Applied Sciences, 5(9), 91-100.

Filippou, F. (2015). The First Woman's Dancer Improvisation in the Area of Roumlouki (Alexandria) through the Dance "Tis Marias". Ethnologia, 6, 1-24.

Garrison, D. R., Anderson, T., \& Archer, W. (2000). Critical inquiry in a text-based environment: Computer conferencing in higher education. The Internet and Higher Education, 2(2-3), 87-105.

Garrison, D., Cleveland-Innes, M., \& Fung, T. (2010). Exploring causal relationships among teaching, cognitive and social presence: Student perceptions of the community of inquiry framework. Internet and Higher Education, 13, 31-36.

Giannousi, M., Vernadakis, N., Derri, V., Antoniou, P., \& Kioumourtzoglou, E. (2014). A comparison of student knowledge between traditional and blended instruction in a physical education in early childhood course. Turkish Online Journal of Distance Education, 15(1), 99-113.

Green, B.S., \& Salkind, J.N. (2013). Using SPSS for Windows and Macintosh: Analyzing and understanding data (7th Ed.). New Jersey: Prentice Hall.

Hosler, K. A., \& Arend, B. D. (2012). The importance of course design, feedback, and facilitation: student perceptions of the relationship between teaching presence and cognitive presence. Educational Media International, 49(3), 217-229.

Jackson, L. C., Jones, S. J., \& Rodriguez, R. C. (2010). Faculty actions that result in student satisfaction in online courses. Journal of Asynchronous Learning Networks, 14(4), 78-96.

Kanuka, H., \& Garrison, D. R. (2004). Cognitive presence in online learning. Journal of Computing in Higher Education, 15(2), 21-39.

Kuo, Y. C., Walker, A., Belland, B. R., \& Schroder, K. E. (2013). A predictive study of student satisfaction in online education programs. The International Review of Research in Open and Distance Learning, 14(1), 16-39.

Kuo, Y. C., Walker, A. E., Schroder, K. E., \& Belland, B. R. (2014). Interaction, Internet self-efficacy, and self-regulated learning as predictors of student satisfaction in online education courses. The Internet and Higher Education, 20, 35-50.

Kupczynski, L., Ice, P., Wiesenmayer, R., \& McCluskey, F. (2010). Student perceptions of the relationship between indicators of teaching presence and success in online courses. Journal of Interactive Online Learning, 9(1), 23-43.

Kyrgiridis, P., Derri, V., Emmanouilidou, K., Chlapoutaki, E., \& Kioumourtzoglou, E. (2014). Development of a Questionnaire for selfevaluation of teacher effectiveness in physical education (SETEQ-PE). Measurement in Physical Education and Exercise Science, 18(2), 73-90.

Ladyshewsky, R. K. (2013). Instructor presence in online courses and student satisfaction. International Journal for the Scholarship of Teaching and Learning, 7(1), 1-23.

Lear, J. L., Isernhagen, J. C., LaCost, B. A., \& King, J. W. (2009). Instructor presence for web-based classes. The Delta Pi Epsilon Journal, 51(2), 86-98.

Mackey, K. R. M., \& Freyberg D.L. (2010). The effect of social presence on affective and cognitive learning in an international engineering course taught via distance-learning. Journal of Engineering Education, 99(1), 23-34.

Mayne, L. A., \& Wu, Q. (2011). Creating and measuring social presence in online graduate nursing courses. Nursing Education Perspectives, 32(2), 110-114.

Robb, C. A., \& Sutton, J. (2014). The importance of social presence and motivation in distance learning. Journal of Technology, Management \& Applied Engineering, 31(1-3), 1-10.

Scollins-Mantha, B. (2008). Cultivating social presence in the online learning classroom: A literature review with recommendations for practice. International Journal of Instructional Technology \& Distance Learning, 5(3), 1-15.

Shea, P. J., Pickett, A. M. \& Peltz, W. E. (2003). A follow-up investigation of teaching presence in the SUNY learning network. Journal of Asynchronous Networks, 7(2), 61-80.

Sung, E., \& Mayer, R. E. (2012). Five facets of social presence in online distance education. Computers in Human Behavior, 28(5), 1738-1747.

Vernadakis, N., Antoniou, P., Giannousi, M., Zetou, E., \& Kioumourtzoglou, E. (2011). The effect of information literacy on physical education students' perception of a course management system. Learning, Media and Technology, 36(4), 419-435.

Vernadakis, N., Antoniou, P., Zetou, E., Kioumourtzoglou, E. (2004). Comparison of three different instructional methods on teaching the skill of shooting in basketball. Journal of Human Movement Studies, 46(5), 421-440.

Vernadakis, N., Derri, V., Tsitskari, E., Antoniou, P. (2014). The effect of Xbox Kinect intervention on balance ability for previously injured young competitive male athletes: A preliminary study. Physical Therapy in Sport, 15(3), 148-155.

Vernadakis, N., Giannousi, M., Tsitskari, E., Antoniou, P., \& Kioumourtzoglou, E. (2012). A comparison of student satisfaction between traditional and blended technology course offerings in physical education. Turkish Online Journal of Distance Education, 13(1), 137-147.

Vernadakis, N., Kouli, O., Tsitskari, E., Gioftsidou, A., \& Antoniou, P. (2014). University students' ability-expectancy beliefs and 
subjective task values for exergames. Computers and Education, 75, 149-161.

Vernadakis, N., Papastergiou, M., Zetou, E., Antoniou, P. (2015). The impact of an exergame-based intervention on children's fundamental motor skills. Computers and Education, 83, 90-102.

Vernadakis, N., Zetou, E., Antoniou, P., \& Kioumourtzoglou, E. (2002). The effectiveness of computer-assisted instruction on teaching the skill of setting in volleyball. Journal of Human Movement Studies, 43(2), 151-164.

Vernadakis, N., Zetou, E., Avgerinos, A., Giannousi, M., \& Kioumourtzoglou, E. (2006). The effects of multimedia computer-assisted instruction on middle school students' volleyball performance. The Engineering of Sport 6(3), 221-226.

Vernadakis, N., Zetou, E., Tsitskari, E., Giannousi, M., \& Kioumourtzoglou, E. (2008). Student attitude and learning outcomes of multimedia computer-assisted versus traditional instruction in basketball. Education and Information Technologies, 13(3), 167183.

Wei, C., Chen, N., \& Kinshuk. (2012). A model for social presence in online classrooms. Educational Technology Research and Development, 60(3), 529-545.

Zetou, E., Amprasi, E., Michalopoulou, M., Aggelousis, N. (2011). Volleyball coaches behavior assessment through systematic observation. Journal of Human Sport and Exercise, 6(4), 585-593.

Zetou, E., Malliou, P., Lola, A., Tsigganos, G., Godolias, G. (2006). Factors related to the incidence of injuries' appearance to volleyball players. Journal of Back and Musculoskeletal Rehabilitation, 19(4), 129-134.

Zetou, E., Nikolaos, V., Evaggelos, B. (2014). The effect of instructional self-talk on performance and learning the backstroke of young swimmers and on the perceived functions of it. Journal of Physical Education and Sport, 14(1), 27-35.

Zetou, E., Vernadakis, N., Bebetsos, E., Makraki, E. (2012). The effect of self-talk in learning the volleyball service skill and self-efficacy improvement. Journal of Human Sport and Exercise, 7(4), 794-805. 